\author{
Michał DUDA ${ }^{1}$ \\ Jurij DOBRIAŃSKI ${ }^{2}$ \\ Daniel CHLUDZIŃSKI ${ }^{3,4}$
}

\title{
CYKLICZNY TERMOSYFON ODWRÓCONY O DWÓCH CZYNNIKACH ROBOCZYCH
}

\begin{abstract}
Dwufazowy termosyfon odwrócony jest urządzeniem umożliwiającym pasywny transport ciepła w przypadku kiedy źródło ciepła usytuowane jest powyżej miejsca jego odbioru. W pracy przedstawiono analizę pracy cyklicznego termosyfonu dwufazowego z dwoma czynnikami roboczymi i wykorzystaniem fazy ciekłej jednego z nich jako nośnika ciepła. Badane urządzenie składało się z dwóch naczyń roboczych usytuowanych jedno nad drugim i umieszczonych nad zasobnikiem wody, do którego ciepło było transportowane oraz grzałki elektrycznej podłączonej do dolnego naczynia roboczego w celu symulowania źródła ciepła. Badania przeprowadzono $\mathrm{w}$ warunkach nieustalonego nagrzewania wody $\mathrm{w}$ zasobni$\mathrm{ku}$ oraz ustalonego strumienia ciepła odpowiednio 300, 600 i $900 \mathrm{~W}$ doprowadzonego do dolnego naczynia roboczego. Odległość na jaką ciepło było transportowane w dół wynosiła 1,5 m. W zależności od wielkości strumienia ciepła dostarczonego do urządzenia, średni przepływ ciekłej fazy nośnika ciepła w obiegu wyniósł odpowiednio 18,$6 ; 27,5$ i $40 \mathrm{dm}^{3} / \mathrm{h}$ przy różnicy temperatur w gałęziach obiegu $11 ; 15,6$ oraz $16^{\circ} \mathrm{C}$.
\end{abstract}

Słowa kluczowe: pasywny transport ciepła, termosyfon dwufazowy, cykliczny termosyfon odwrócony, termosyfon z dwoma czynnikami roboczymi

\section{Wprowadzenie}

Najprostszym, najbardziej niezawodnym i najtańszym sposobem transportu energii termicznej są układy o naturalnej konwekcyjnej cyrkulacji płynu. Nie zawsze jednak ten sposób może być wykorzystany, np. instalacje słoneczne z kolektorem usytuowanym powyżej zasobnika wody ogrzewanej, wówczas stosowane są obiegi cieczowe o cyrkulacji nośnika ciepła wymuszonej pompą

${ }^{1}$ Autor do korespondencji: Michał Duda, Uniwersytet Warmińsko-Mazurski, ul. Oczapowskiego 11, 10-736 Olsztyn, tel. 8952461 57, michal.duda@uwm.edu.pl

2 Jurij Dobriański, dobr@uwm.edu.pl

${ }^{3}$ Daniel Chludziński, daniel.chludzinski@uwm.edu.pl

${ }^{4}$ Autor otrzymał stypendium wspóffinansowane przez Unię Europejską w ramach Europejskiego Funduszu Społecznego 
zasilaną energią elektryczną. Niemniej jednak w przeszłości badane były pasywne urządzenia pozwalające na transport ciepła w kierunku przeciwnym do konwekcji naturalnej. W dużej mierze są to klasyczne rury ciepła [6, 14], pętlowe rury ciepła [13] oraz kapilarnie pompujące pętle [1]. Chociaż w przypadku tych dwóch ostatnich wpływ siły grawitacji na pracę urządzenia jest niewielki [15], to wykonanie kapilarnej struktury jest procesem technologicznie złożonym i kosztownym. Inną grupę urządzeń do transportu ciepła, pracujących przeciwko sile grawitacji stanowią dwufazowe termosyfony znane z literatury jako: pompująca w dół rura ciepła [3], termosyfon odwrócony [12], pasywny parowy system transportu [8], czy też spontaniczny system transportu ciepła w dół [2]. Chociaż nazwy tych urządzeń się różnią, to ich działanie oparte jest na okresowym, naprzemiennym transporcie ciepła za pośrednictwem pary od parownika do skraplacza i powrocie kondensatu ze skraplacza do parownika, przez co mogą być określone jako okresowy dwufazowy termosyfon [7]. Z uwagi na to, iż transport ciepła w dół za pośrednictwem pary wymaga późniejszego podnoszenia kondensatu ze skraplacza do parownika, to wraz ze wzrostem odległości na jaką ciepło to jest transportowane, wrasta wewnętrzna różnica temperatury i ciśnienie pary w urządzeniu [9] a urządzenia takie nie mogą być stosowane przy transporcie ciepła w dół na większe odległości [11]. Problem tak znacznego wpływu wysokości obiegu na pracę urządzenia nie występuje, kiedy nośnikiem ciepła jest ciecz. W tym przypadku, przy niewielkiej różnicy temperatury wewnątrz urządzenia, ogrzana ciecz może być przetłaczana nawet do kilkuset metrów [4]. Duże obiegi z uwagi na koszt i względy ekologiczne uniemożliwiają wykorzystanie jako czynnika roboczego substancji chłodniczej. W tym przypadku rozwiązaniem jest zastosowanie wody, która jednak ze względu na dużą wartość podciśnienia w obiegu przy temperaturze pracy poniżej $100^{\circ} \mathrm{C}$ [10], sprawia wiele problemów [4].

W pracy przedstawiono zasadę działania oraz wyniki badań cyklicznie pracującego dwufazowego termosyfonu odwróconego z dwoma czynnikami roboczymi: wodą i pentanem. Takie rozwiązanie ma zapewnić nadciśnienia wewnątrz obiegu przy temperaturze pracy poniżej $100^{\circ} \mathrm{C}$ i jednoczesne ograniczenie zastosowanie substancji chłodniczej.

\section{Cykliczny termosyfon odwrócony $\mathrm{z}$ dwoma czynnikami ro- boczymi - budowa i zasada działania}

Termosyfon odwrócony $\mathrm{z}$ dwoma czynnikami roboczymi składa się z dwóch naczyń roboczych oraz przeponowego wymiennika ciepła (rys. 1). Naczynie robocze umieszczone są jedno nad drugim, natomiast wymiennik znajduje się poniżej tych naczyń w zasobniku wody ogrzewanej. Ciepło doprowadzane jest do naczynia roboczego dolnego zwanego naczyniem ciepłym. Naczynie to, za pośrednictwem gałęzi ciepłej-opadowej połączone jest z wy- 
miennikiem. Z drugiej strony wymiennik gałęzią zimną-podnośną połączony jest $\mathrm{z}$ naczyniem górnym zimnym. Dodatkowo naczynia robocze połączone są kanałem pośrednim i rurą przepustową. $\mathrm{W}$ celu zapewnienia odpowiedniego kierunku przepływu cieczy i pary w urządzeniu, w gałęzi podnośnej oraz w kanale pośrednim zamontowano zawory zwrotne oraz zawór sterujący na wlocie rury przepustowej [5].

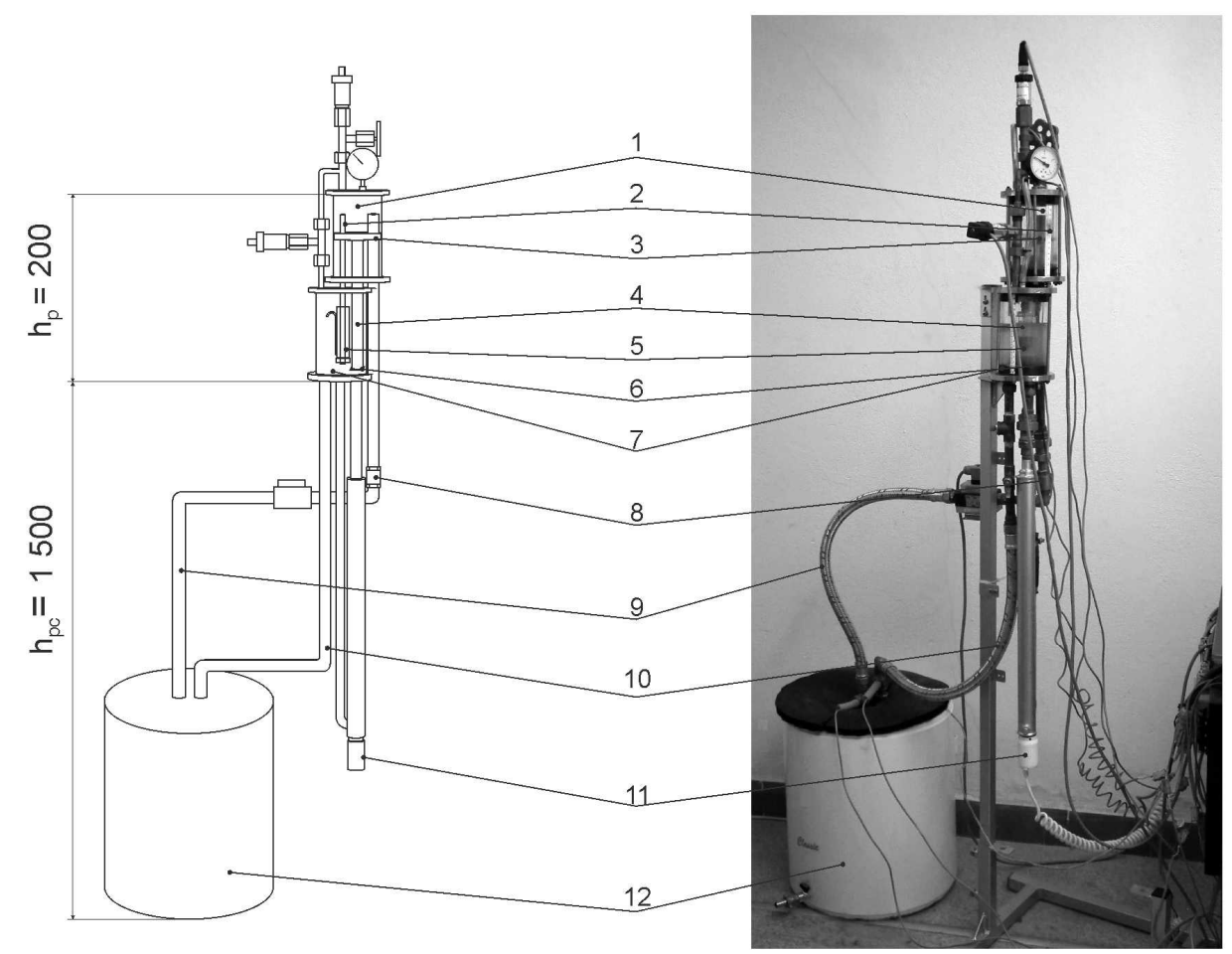

Rys. 1. Schemat stanowiska laboratoryjnego: 1 - naczynie robocze zimne, 2 - rura przepustowa, 3 - lejek zbierający, 4 - kanał pośredni, 5 - zawór sterujący cieczowy, 6 - zawór zwrotny, 7 naczynie robocze ciepłe, 8 - zawór zwrotny, 9 - gałąź zimna-podnośna, 10 - gałąź ciepłaopadowa, 11 - grzałka elektryczna, 12 - zasobnik wody ogrzewanej, $\mathrm{h}_{\mathrm{pc}}$ - wysokość przenoszenia ciepła (1500), $\mathrm{h}_{\mathrm{p}}$ - wysokość podnoszenia cieczy (200)

Fig. 1. Schematic laboratory stand: 1 - cold fluid vessel, 2 - passage pipe 3 - collecting funnel, 4 - intermediate channel, 5 - control valve of liquid seal type, 6 - check valves, 7 - hot fluid vessel, 8 - check valve, 9 - cold rising branch, 10 - hot falling branch, 11 - electric heater, 12 -heat water tank, $\mathrm{h}_{\mathrm{pc}}$ - heat transport height (1500), $\mathrm{h}_{\mathrm{p}}$ - liquid transport height (200)

Termosyfon pracuje cyklicznie. Na cykl pracy składa się okres pompowania cieczy przez przeponowy wymiennik ciepła oraz okres powrotu cieczy z naczynia górnego do naczynia dolnego, przy czym w tym ostatnim występuje jednoczesny przepływ nadmiaru pary z naczynia dolnego do górnego. Wskutek 
doprowadzenia ciepła do naczynia dolnego, wzrasta temperatura cieczy oraz ciśnienie pary w tym naczyniu. W momencie, kiedy ciśnienie pary czynników roboczych (woda i pentan) w naczyniu dolnym przekroczy wartość ciśnienia pary w naczyniu górnym powiększoną o ciśnienie hydrostatyczne różnicy poziomów cieczy w tych naczyniach oraz opory hydrauliczne przepływu cieczy przez obieg wymiennika ciepła, następuje wypieranie ogrzanej cieczy z naczynia dolnego. Ciepła ciecz wyparta z naczynia dolnego przepływa przez przeponowy wymiennik ciepła, gdzie zostaje odebrane od niej ciepło w zasobniku wody ogrzewanej. Schłodzona ciecz trafia do naczynia górnego. W naczyniu górnym ciecz jest gromadzona do czasu zakończenia okresu pompowania. Przy odpowiednio niskim poziomie cieczy w naczyniu dolnym następuje automatyczne otwarcie pływakowo-cieczowego zaworu sterującego. W tym momencie nadmiar pary z naczynia dolnego przepływa rurą przepustową do naczynia górnego, po czym kanałem pośrednim następuje grawitacyjny powrót cieczy (woda i pentan) z naczynia górnego do dolnego. Pompowanie cieczy zachodzi przy zamkniętym zaworze sterującym, w tym czasie zawór zwrotny kanału pośredniego pozostaje zamknięty, natomiast zawór w gałęzi podnośnej - otwarty. Podczas powrotu cieczy z naczynia górnego do dolnego, zawór sterujący i zawór jednokierunkowy w kanale pośrednim są otwarte, natomiast zawór zwrotny w gałęzi podnośnej jest zamknięty.

\section{Badania laboratoryjne}

Badania laboratoryjne obiegu $\mathrm{z}$ termosyfonem odwróconym przeprowadzono w warunkach nieustalonego nagrzewania cieczy w zasobniku i przy ustalonym strumieniu ciepła doprowadzonego do urządzenia. W tym celu wykorzystano izolowany termicznie zbiornik o pojemności $25 \mathrm{dm}^{3}$. Wewnątrz tego zbiornika umieszczono przeponowy wymiennik ciepła wykonany ze spiralnie zwiniętej rury miedzianej o średnicy zewnętrznej $18 \mathrm{~mm}$, długości $1 \mathrm{~m}$. $\mathrm{W}$ zbiorniku dodatkowo zamontowano mieszadło mechaniczne do wyrównywania pola temperatury cieczy. Jako źródło ciepła zastosowano grzałkę elektryczną o mocy $1,5 \mathrm{~kW}$ podłączoną do sieci elektrycznej za pośrednictwem autotransformatora. Strumień ciepła od grzałki do urządzenia był doprowadzany niezależnie od fazy cyklu pracy (okres pompowania i okres grawitacyjnego powrotu czynników roboczych). Instalacja laboratoryjna wypełniona była dwoma czynnikami roboczymi: wodą w ilości 4 litrów i pentanem w ilości 50 mililitrów. Eksperymenty przeprowadzono dla trzech wielkości strumienia ciepła: 300, 600 i $900 \mathrm{~W}$. Na początku każdego eksperymentu temperatura wody w zasobniku wynosiła $20^{\circ} \mathrm{C}$. Eksperyment przerywano w momencie, gdy temperatura wody w zasobniku przekroczyła $40^{\circ} \mathrm{C}$.

Podczas eksperymentów do pomiaru temperatury zastosowano czujniki termoelektryczne typu K o średnicy osłony $1 \mathrm{~mm}$. Chwilowej wartości prze- 
pływu cieczy w obiegu przeponowego wymiennika ciepła dokonano przy wykorzystaniu przepływomierza elektromagnetycznego MIK o zakresie pomiarowym $0,16 \div 3,2 \mathrm{dm}^{3} \mathrm{~min}^{-1}$. Wielkości mierzone odczytywano i zapisywano z częstotliwością $1 \mathrm{~Hz}$. Podczas eksperymentów rejestrowana również była chwilowa moc elektryczna pobierana przez grzałkę.

\section{Wyniki i dyskusja}

Wyniki z przeprowadzonych eksperymentów dla strumienia ciepła doprowadzonego 300, 600 i $900 \mathrm{~W}$ przedstawiono w postaci wykresów na rysunkach 2,3 i 4. Wykresy obrazują przebieg zmiany temperatury cieczy na wyjściu i powrocie do urządzenia oraz średniej wartości przepływu cieczy przez przeponowy wymiennik ciepła $\mathrm{w}$ zależności od temperatury zasobnika wody ogrzewanej. Chwilowa wartość przepływu cieczy na wykresach została przedstawiona jako średnia ruchoma z okresem uśrednienia 60 .

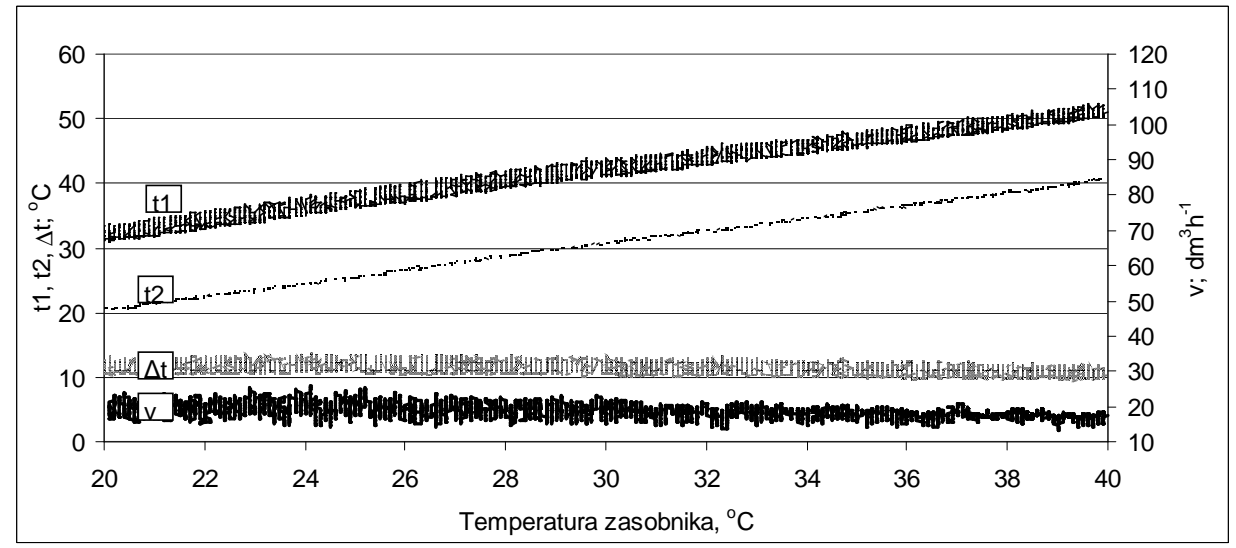

Rys. 2. Zależność pomiędzy: temperaturą zasobnika, temperaturą płynu na wylocie i wlocie do urządzenia oraz prędkością przepływu cieczy w obiegu. Strumień ciepła $-300 \mathrm{~W}$

Fig. 2. Dependence between: temperature of tank, temperature of fluid on the inlet and outlet of device as well as velocity of fluid flow in circulation. The heat flux $-300 \mathrm{~W}$

Dostrzegalne wahania temperatury $\mathrm{t} 1$ na wyjściu $\mathrm{z}$ urządzenia wynikają bezpośrednio z cyklicznego charakteru pracy urządzenia. Ponieważ po otwarciu zaworu sterującego do naczynia dolnego ciepłego powraca grawitacyjnie zimna mieszanina cieczy czynników roboczych (pentan i woda), to w chwili rozpoczęcia pompowania cieczy przez wymiennik ciepła, temperatura wody i pentanu $\mathrm{w}$ naczyniu dolnym jest najniższa. Późniejszy wzrost temperatury czynników roboczych w naczyniu dolnym spowodowany jest głównie zwiększeniem różnicy poziomów cieczy w naczyniach roboczych w wyniku okresowego gromadzenia zimnej cieczy w naczyniu górnym. 


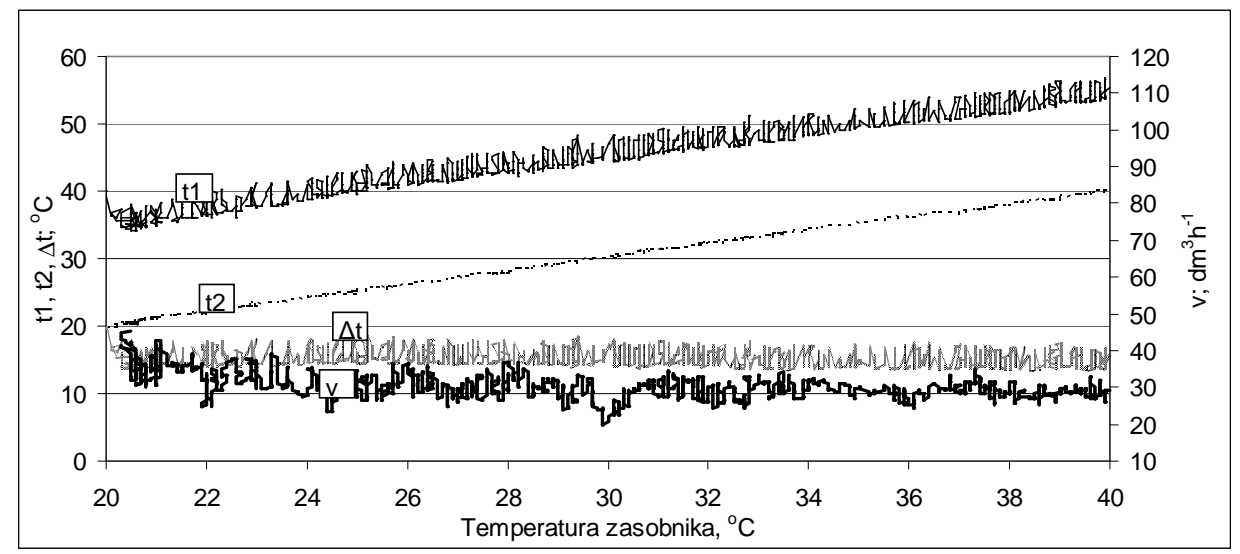

Rys. 3. Zależność pomiędzy: temperaturą zasobnika, temperaturą płynu na wylocie i wlocie do urządzenia oraz prędkością przepływu cieczy w obiegu. Strumień ciepła $-600 \mathrm{~W}$

Fig. 3. Dependence between: temperature of tank, temperature of fluid on the inlet and outlet of device as well as velocity of fluid flow in circulation. The heat flux $-600 \mathrm{~W}$

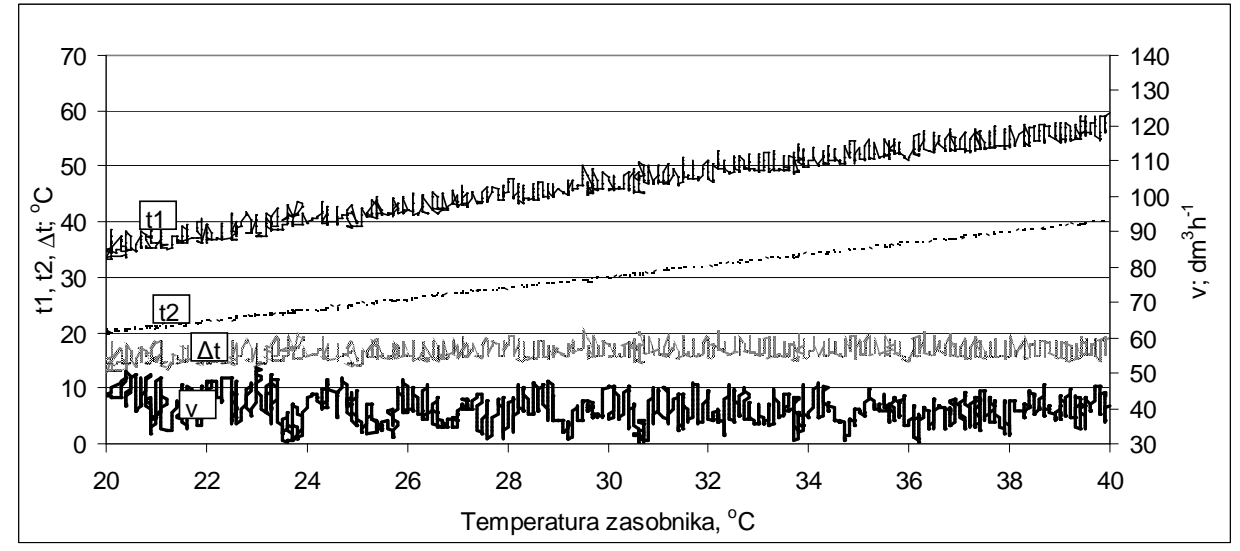

Rys. 4. Zależność pomiędzy: temperaturą zasobnika, temperaturą płynu na wylocie i wlocie do urządzenia oraz prędkością przepływu cieczy w obiegu. Strumień ciepła - $900 \mathrm{~W}$

Fig. 4. Dependence between: temperature of tank, temperature of fluid on the inlet and outlet of device as well as velocity of fluid flow in circulation. The heat flux $-900 \mathrm{~W}$

Podczas eksperymentów zaobserwować można było nieznaczny wpływ zmiany wielkości strumienia ciepła dostarczonego do urządzenia na różnicę temperatury cieczy w gałęziach obiegu. Zauważalna natomiast była zależność średniej wartości przepływu wody przez przeponowy wymiennik ciepła od wielkości strumienia ciepła doprowadzonego. Wraz ze wzrostem strumienia ciepła przepływ zwiększył się i wynosił odpowiednio: $18,6 \mathrm{dm}^{3} \mathrm{~h}^{-1}$ przy strumieniu ciepła 
doprowadzonego $300 \mathrm{~W}, 27,5 \mathrm{dm}^{3} \mathrm{~h}^{-1}$ przy strumieniu $600 \mathrm{~W}$ i $40 \mathrm{dm}^{3} \mathrm{~h}^{-1}$ dla strumienia $900 \mathrm{~W}$.

\section{Podsumowanie}

Badania laboratoryjne potwierdziły możliwość stosowania dwóch czynników roboczych w obiegu. Zaproponowane urządzenie pracowało stabilnie

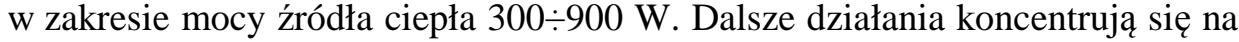
przystosowaniu modelu laboratoryjnego do współpracy z instalacją o wysokości powyżej $10 \mathrm{~m}$. Planowane są również eksperymenty, w których grzałka elektryczna zostanie zastąpiona kolektorem słonecznym.

\section{Literatura}

[1] Bazzo E., Riehl R.: Operation characteristics of a small-scale capillary pumped loop, Appl. Thermal Eng., 23 (2003) 687-705.

[2] Beni G. de, Friesen R.: Spontaneous downward heat transport comparison tests of an improved system, Solar Energy, 50 (1993) 27-34.

[3] Bienert W., Pravda M.: Down-pumping heat pipes. Google Patents, 1977, http://www.google.com/patents/US4050509 [dostęp: 28 marca 2014 r.].

[4] Dobriansky Y., Yohanis Y.: Cyclical reverse thermosiphon, Arch. Thermodynamics, 31 (2010) 3-32.

[5] Dobriański J., Chludziński D., Duda M., Piechocki J., Samsel M., Wójcik R., Sposób samoczynnego przekazywania ciepła w kierunku odwrotnym do konwekcji naturalnej i urządzenie do samoczynnego przekazywania ciepła w kierunku odwrotnym do konwekcji naturalnej, WYN: 217073, 2010.

[6] Faghri A.: Heat pipe science and technology, Taylor \& Francis, Washington, DC, 1995.

[7] Filippeschi S.: On periodic two-phase thermosyphons operating against gravity, Int. J. Thermal Sci., 45 (2006) 124-137.

[8] Hedstrom J. C.: Vapor phase heat transport systems, 1984.

[9] Kadoguchi K., Yamazaki M.: Intermittent heat transportation by discharge of accumulated vapor, Appl. Thermal Eng., 24 (2004) 2761-2775.

[10] Koito Y., Ahamed M. S., Harada S., Imura H.: Operational characteristics of a topheat-type long heat transport loop through a heat exchanger, Appl. Thermal Eng., 29 (2009) 259-264.

[11] Koito Y., Ikemizu Y., Tomimura T., Mochizuki M., A vapor-pressure-driven heat pipe for sideward long-distance heat transport, Frontiers Heat Pipes, 1 (2010) 1-7.

[12] Nasonov E. A., Bondarenko I.: Heat-transmission device for solar heating systems, Appl. Solar Energy, 16 (1980) 59-64.

[13] Pastukhov V., Maidanik Y., Vershinin C., Korukov M.: Miniature loop heat pipes for electronics cooling, Appl. Thermal Eng., 23 (2003) 1125-1135. 
[14] Peterson G.: An introduction to heat pipes. Modeling, testing and applications, Wiley series in thermal management of microelectronic and electronic systems, Wiley, New York, 1994.

[15] Vasiliev L. L.: Heat pipes in modern heat exchangers, Appl. Thermal Eng., 25 (2005) 1-19.

\section{CYCLICAL REVERSE THERMOSIPHON WITH TWO WORKINGMEDIA}

\section{S u m m a r y}

A two-phase reverse thermosiphon is a device which allows for passive a heat transfer while heat source is situated above the delivery point. In the paper an analysis of the two-phase reverse thermosiphon operating with two working media and the use of liquid phase one of them as a heat carrier was presented. The investigated equipment was consisted of two vessels and electric heating element connected to lower working vessels in the order to simulate of the heat source. The vessels are situated one above another and placed in contained to which the heat was transferred. The research was performed in the conditions of transient water heating in a container and steadystate heat flux at the three various levels of $300 \mathrm{~W}, 600 \mathrm{~W}$ and $900 \mathrm{~W}$ led to the lower working vessel. Heat was transferred downwards at a distance of $1.5 \mathrm{~m}$. Depending on the heat flux supplied to the device, average flow velocity of liquid in the cycle was $18.6 ; 27.5$ and $40 \mathrm{dm}^{3} \mathrm{~h}^{-1}$ for the temperature difference $11 ; 15.6$ and $16^{\circ} \mathrm{C}$, respectively.

Keywords: passive heat transport, two-phase thermosyphon, cyclical reversed thermosyphon, thermosiphon with two working media

DOI: $10.7862 / \mathrm{rm} .2014 .20$

Otrzymano/received: 15.05 .2014

Zaakceptowano/accepted: 27.05.2014 